\title{
CONF-950904--4
}

\section{FLOW EXCURSION TIME SCALES IN THE ADVANCED NEUTRON SOURCE REACTOR}

\author{
C. D. Sulfredge \\ Oak Ridge National Laboratory ${ }^{1}$ \\ Martin Marietta Energy Systems, Inc. \\ Bldg. 9204-1, MS-8045 \\ Oak Ridge, TN 37831-8045
}

\begin{abstract}
Flow excursion transients give rise to a key thermal limit for the proposed Advanced Neutron Source (ANS) reactor because its core involves many parallel flow channels with a common pressure drop. Since one can envision certain accident scenarios in which the thermal limits set by flow excursion correlations might be exceeded for brief intervals, a key objective is to determine how long a flow excursion would take to bring about a system failure that could lead to fuel damage. The anticipated time scale for flow excursions has been examined by subdividing the process into its component phenomena: bubble nucleation and growth, deceleration of the resulting two-phase flow, and finally overcoming thermal inertia to heat up the reactor fuel plates. Models were developed to estimate the time required for each individual stage. Accident scenarios involving sudden reduction in core flow or core exit pressure have been examined, and the models compared with RELAP5 output for the ANS geometry. For a high-performance reactor like the ANS, flow excursion time scales were predicted to be in the millisecond range, so that even very brief transients might lead to fuel damage. These results should prove useful whenever one must determine the time involved in any portion of a flow excursion transient.
\end{abstract}

\section{Nomenclature}

$\begin{array}{ll}\text { b } & \text { Channel gap }(\mathrm{m}) \\ \mathbf{c}_{\mathrm{p}} & \text { Specific heat }(\mathrm{J} / \mathrm{kgK}) \\ \mathrm{D}_{\mathbf{H}} & \text { Hydraulic diameter }(\mathrm{m}) \\ \dot{E}_{\text {gen }} & \text { Internal heat generation rate }(\mathrm{W}) \\ \mathbf{f} & \text { Moody friction factor } \\ \mathrm{g} & \text { Acceleration due to gravity }\left(=9.81 \mathrm{~m} / \mathrm{s}^{2}\right) \\ \mathbf{G} & \text { Coolant mass flux }\left(\mathrm{kg} / \mathrm{m}^{2} \mathrm{~s}\right) \\ \mathbf{h} & \text { Convective heat transfer coefficient }\left(\mathrm{W} / \mathrm{m}^{2} \mathrm{~K}\right) \\ \mathbf{h}_{\mathrm{fg}} & \text { Enthalpy of vaporization }(\mathrm{J} / \mathrm{kg}) \\ \mathrm{Ja} & \text { Jakob number }\left[\left(\mathrm{T}_{\mathrm{w}}-\mathrm{T}_{\mathrm{sa}}\right) \mathrm{c}_{\mathrm{p}} \rho_{\mathrm{g}} /\left(\mathrm{h}_{\mathrm{fg}} \rho_{\mathrm{v}}\right)\right] \\ \mathbf{k} & \text { Thermal conductivity }(\mathrm{W} / \mathrm{mK}) \\ \mathbf{L} & \text { Channel length }(\mathrm{m}) \\ \mathbf{P} & \text { Pressure }(\mathrm{Pa})\end{array}$

\footnotetext{
'The submitted manuscript has been authored by a contractor of the U.S. Government under contract DE-AC05-84OR21400. Accordingly, the U.S. Government retains a nonexclusive, royalty-free license to publish or reproduce the published form of this contribution, or allow others to do so, for U.S. Government purposes. Energy.

Managed by Martin Marietta Energy Systems, Inc., under contract DE-AC05-84OR21400 with the U.S. Department of
} 


\section{DISCLAIMER}

Portions of this document may be illegible in electronic image products. Images are produced from the best available original document. 


$\begin{array}{ll}\mathrm{q}^{\prime \prime} & \text { Heat flux }\left(\mathrm{W} / \mathrm{m}^{2}\right) \\ \mathbf{r} & \text { Radius }(\mathrm{m}) \\ \mathrm{R}^{+} & \text {Normalized bubble radius } \\ \mathbf{s} & \text { Channel span }(\mathrm{m}) \\ \mathbf{t} & \text { Time }(\mathrm{s}) \\ \mathrm{t}^{+} & \text {Normalized time } \\ \mathrm{T} & \text { Temperature }(\mathrm{K}) \\ \mathrm{V} & \text { Velocity }(\mathrm{m} / \mathrm{s}) \\ \mathbf{x}(\mathrm{z}) & \text { Thermodynamic flow quality } \\ \mathbf{x}^{\prime}(\mathrm{z}) & \text { Flow vapor mass fraction } \\ \mathrm{Y}_{\mathrm{b}} & \text { Actual bubble radius at detachment }(\mathrm{m}) \\ Y_{b}^{+} & \text {Normalized bubble size at detachment } \\ \mathrm{z} & \text { Axial coordinate }(\mathrm{m})\end{array}$

\section{Greek Symbols}

$\begin{array}{ll}\alpha(\mathrm{z}) & \text { Flow void fraction } \\ \alpha & \text { Liquid thermal diffusivity }\left(\mathrm{m}^{2} / \mathrm{s}\right) \\ \varepsilon & \text { Surface roughness }(\mathrm{m}) \\ \mu & \text { Dynamic viscosity }\left(\mathrm{Ns} / \mathrm{m}^{2}\right) \\ \rho & \text { Mass density }\left(\mathrm{kg} / \mathrm{m}^{3}\right) \\ \sigma & \text { Surface tension }(\mathrm{N} / \mathrm{m}) \\ \tau & \text { Surface shear stress }\left(\mathrm{N} / \mathrm{m}^{2}\right) \\ \phi^{2} & \text { Two-phase friction multiplier }\end{array}$

\section{Subscripts}

$\begin{array}{ll}\text { b } & \text { Bubble } \\ \text { c } & \text { Cavity } \\ \text { CHF } & \text { Critical heat flux } \\ \text { e } & \text { Channel exit } \\ \text { f } & \text { Friction } \\ \text { i } & \text { Channel inlet } \\ 1 & \text { Liquid } \\ \text { sat } & \text { Saturation conditions } \\ \text { v } & \text { Vapor } \\ \text { w } & \text { Wall surface } \\ 1 \phi & \text { One-phase } \\ 2 \phi & \text { Two-phase }\end{array}$

\section{INTRODUCTION}

The Advanced Neutron Source (ANS) reactor is currently being designed to generate the world's highest steady-state thermal neutron fluxes for use in scattering experiments. As a result, the ANS reactor core operates with a very high power density, and thus with a very high heat flux from the fuel plates. The current reference design for the core uses aluminum-clad fuel plates packed in an involute geometry to 
form parallel flow channels between common upper and lower plenums. To achieve the desired power density, a narrow channel gap of $1.27 \mathrm{~mm}$ is planned, together with a $507-\mathrm{mm}$ heated length and a nominal coolant velocity of $25 \mathrm{~m} / \mathrm{s}$. The nominal average and peak heat fluxes are approximately 6 and $12 \mathrm{MW} / \mathrm{m}^{2}$, respectively. Such a parallel-plate core is potentially vulnerable to fuel damage resulting from excursive flow instability, which represents the most restrictive thermal limit for the ANS under most operating conditions.

Flow excursion instability was first investigated by Ledinegg [1], and differs from a true critical heat flux (CHF) failure because the mass flow rate in the affected channel is not constant. The mechanism of flow excursion is most easily visualized in terms of supply and demand curves for the channel pressure drop as functions of flow rate. As illustrated in Fig. 1, the demand curve representing the pressure difference necessary to force coolant through a particular heated channel has a characteristic " $S$ " shape. At very high coolant velocities, the flow will be entirely single-phase liquid, while extremely low flow rates would give rise to single-phase vapor flow in the channel. Both these situations have typical positively-sloped demand curves in which the flow rate is directly related to pressure drop. When the coolant velocity approaches intermediate values where two-phase flow appears, the channel demand characteristic begins to deviate from the single-phase liquid and vapor curves. The region of the demand curve with significant two-phase flow present is marked by a negative slope, as seen in Fig. 1. Two-phase effects first appear in a singlephase liquid flow at the point of incipient boiling (IB) and become pronounced with the onset of significant voiding (OSV) in the fluid. In contrast to the demand pressure drop for each channel, which depends on the flow through it, the supply pressure differential available to drive the flow is only a function of the pressure in the common inlet and outlet plenums, which will be identical for all the parallel channels. Hence, the supply curve in Fig. 1 is shown by a horizontal line. Steady-state operation is possible only at points corresponding to an intersection of this supply line with the channel demand curve.

Interaction between the demand and supply curves leads to the phenomenon of flow excursion in a parallel-channel system. Under normal operating conditions in the ANS, the supply pressure drop is given by the upper line, so that the coolant flow is entirely single phase at the operating point $A$. If the nominal supply pressure drop in Fig. 1 were somehow reduced, point A would move down the demand curve until it reached the minimum. Any further decrease in the supply pressure drop to a position such as $\Delta \mathrm{P}_{\text {Supply }}(2)$ would leave no operating intersection available except point $\mathrm{B}$ in the single-phase vapor flow regime. Ledinegg showed that this situation would force the flow to redistribute itself to adjacent parallel channels, so that mass flow in the channel with the highest heat flux would be sharply reduced. A critical heat flux condition would then occur in the affected channel because of flow starvation well before the system reached point B. The difference between the supply and demand curves indicated in Fig. 1 represents a pressure "defect" that decelerates the flow during an excursion. The thermal-hydraulic conditions leading to flow excursion can arise from either a decrease in the available supply pressure drop or from an upward shift of the demand curve minimum due to system depressurization. In a system of parallel channels, accident scenarios usually indicate fuel damage resulting from excursive instability and flow redistribution rather than a true CHF situation at nominal flow rate. 
One of the correlations presently being used by the ANS Project to predict the onset of flow instability was developed by Costa [2] in 1967. Safety margins are defined in terms of a flow excursion limit ratio

$$
\text { Thermal Limit Ratio }=\frac{q_{\text {costa }}^{\prime \prime}}{q_{\text {actua }}^{\prime \prime}}
$$

Thus, as long as the thermal limit ratio remains greater than 1 during a projected accident scenario, no fuel damage should occur. Although the Costa correlation allows one to estimate the conditions that lead to flow excursion, it says nothing about the time scale of the transient leading up to failure. In fact, none of the flow excursion correlations available addresses the transient nature of the problem. This lack of knowledge causes particular problems when analyzing a high-performance research reactor such as the ANS. Figure 2, taken from an ANS progress report [3], shows the RELAP5 MOD3 simulation of a 127$\mathrm{mm}$ diameter pipe break near the ANS primary system vessel adaptor weld (PSVAW), with the flow excursion limit ratio plotted as a function of time. Early in the transient at $t=8.8 \mathrm{~ms}$ and again at $\mathrm{t}=$ $32.5 \mathrm{~ms}$, the flow excursion limit is exceeded as a result of depressurization because of acoustic waves propagating from the point of fracture. The first such period lasts for only $2 \mathrm{~ms}$ and the second lasts for $4 \mathrm{~ms}$. Whether these brief intervals actually allow a flow excursion to take place and cause any fuel plate damage remains unresolved by RELAP5. This paper will examine the transient nature of flow excursion in detail and try to evaluate the time scale required for a flow excursion to develop fully and bring about a system failure under ANS conditions.

\section{MODELING THE STAGES OF FLOW EXCURSION}

The anticipated time scale of flow excursion in the ANS has been examined by recognizing that a flow excursion is actually the net result of several distinct processes. Once conditions necessary to initiate an excursion failure are present, vapor bubble nucleation and growth to detachment size must take place. The resulting two-phase flow then has to be decelerated against the fluid's inertia until a critical heat flux condition occurs. Finally, the thermal inertia of the ANS fuel plates themselves must be taken into account to see how much time elapses between a CHF film-boiling condition and irreversible fuel melting. Depending on the surface characteristics of the ANS fuel plates, the creation of vapor bubbles may also be delayed by the need to form a metastable, superheated liquid prior to nucleation. Models have been developed to estimate the time required for each of these individual stages.

\section{Bubble Growth Time}

To estimate the time required for vapor formation, models for both the bubble size at detachment and the bubble growth rate on a heated surface must be available. The normalized bubble detachment size, $Y_{b}^{+}$, can be found from the work of Levy [4]: 


$$
Y_{b}^{+}=0.015\left(\sigma D_{H} \rho_{l}\right)^{1 / 2} \frac{1}{\mu_{l}}
$$

where $\sigma$ is the liquid surface tension and $D_{H}$ is the channel hydraulic diameter. The expected bubble radius when it leaves the wall can then be calculated from $Y_{b}^{+}$using the relationships

$$
\begin{aligned}
& Y_{b}=Y_{b}^{+}\left(\tau_{w} / \rho_{l}\right)^{1 / 2} \frac{\rho_{l}}{\mu_{l}} \\
& \text { where } \tau_{w}=\frac{f}{8} \frac{G^{2}}{\rho_{l}} \text { and } f=0.0055\left(1+\left[20000\left(\frac{\epsilon}{D_{H}}\right)+\frac{10^{6}}{G D_{H} / \mu_{I}}\right]^{1 / \beta}\right)
\end{aligned}
$$

In all these equations, $G$ represents the mass flux in the flow channel and $f$ stands for the Moody friction factor. Once $Y_{b}$ has been calculated, a model for bubble growth can be invoked to solve for the growth time necessary to attain this radius. A useful relation for bubble radius as a function of time is given by the model of Mikic, et al. [5]:

$$
R^{+}=\frac{2}{3}\left[\left(t^{+}+1\right)^{3 / 2}-\left(t^{+}\right)^{3 / 2}-1\right]
$$

where $R^{+}=\frac{r_{b}}{\left(B^{2} / A\right)}$ is a dimensionless bubble radius and $t^{+}=\frac{t}{\left(B^{2} / A^{2}\right)}$ is a normalized time for bubble growth. The parameters $A$ and $B$ are evaluated using

$$
\begin{gathered}
A=\left[\frac{\pi}{7} \frac{\left(T_{w}-T_{s a t}\right) h_{t g} \rho_{v}}{T_{\text {sat }} \rho_{1}}\right]^{1 / 2} \\
B=\left[\frac{12}{\pi} \mathrm{Ja}^{2} \alpha_{l}\right]^{1 / 2}
\end{gathered}
$$

for bubble growth on a surface of temperature $T_{w}$ where $J a=\frac{\left(T_{w}-T_{s a s}\right) c_{p} \rho_{l}}{h_{f g} \rho_{v}}$ is the Jakob number relating the latent and sensible heats. This solution for the bubble growth time to detachment is valid in both the early inertia-controlled stage of bubble growth and later on when heat diffusion is the limiting factor. 


\section{Fluid Inertia Delay}

After nucleation and bubble growth to detachment, the time required to slow the two-phase flow in the channel must be addressed. This portion of the transient can be modeled by applying the integral momentum equation to a control volume located inside the cooling channel. Figure 3 shows a schematic of the control volume used to analyze two-phase flow in a channel of span $s$, gap $b$, and overall length $L$ under the assumption of one-dimensional flow with uniform velocity and temperature at any crosssection. Neglecting the influence of gravity, which is very minor compared to forced flow effects at ANS flow rates, the forces acting on the control volume are the inlet and exit pressures plus single- and twophase shear forces along the walls. Applying the integral momentum equation then yields

$$
\begin{aligned}
\frac{d V_{i}(t)}{d t} & =\frac{1}{\rho_{i} s b L}\left[\left(P_{i}-P_{e}\right) s b-2(s+b) \tau_{1 \phi}(t) L_{1 \phi}(t)\right. \\
& \left.-\int_{L_{1}}^{L} 2(s+b) \tau_{2 \phi}(t, z) d z-\rho_{i} V_{i}(t) s b\left[V_{e}(t)-V_{i}(t)\right]\right]
\end{aligned}
$$

which is a differential equation for the inlet flow velocity as a function of time. The first term on the right hand side represents the supply pressure drop available to drive the flow, with $P_{d}(t)$ and $P_{e}(t)$ taken to be specified time-dependent boundary conditions that are obtained from the plenum pressures after allowing for inlet and exit losses. The next two terms represent shear forces integrated along the channel in the single-phase regime up to $z=L_{l \phi}(t)$ and in the two-phase region between $L_{l \phi}(t)$ and $L$. The last term on the right is a momentum term arising from acceleration of the flow due to heat input. Invoking the continuity equation gives $V_{e}(t)=V_{i}(t) \rho_{\mathrm{i}} / \rho_{\mathrm{e}}$ for the exit velocity if one neglects any transient accumulation of mass inside the channel. This idealization assumes the vapor mass fraction remains relatively low and the liquid phase is sufficiently incompressible that channel mass inflow and outflow are essentially equal at any time during the transient.

Equation (6) provides a way to reconstruct the channel demand and supply curves analytically and track changes in inlet velocity brought about by flow redistribution as a flow excursion proceeds. To carry out the calculations, several more correlations are necessary. First, one must have some relationship for determining the onset of significant voiding that initiates two-phase flow at $z=L_{16}$. The OSV correlation selected for this analysis is the one proposed by Saha and Zuber [6]:

$$
\begin{array}{ll}
T_{\text {set }}-T_{\text {bulk }}=0.0022\left[\frac{q^{\prime \prime} D_{h}}{k_{I}}\right] & P_{\theta}<70000 \\
\text { or } T_{\text {seat }}-T_{\text {belk }}=153.8\left[\frac{q^{\prime \prime}}{G c_{\rho}}\right] & P_{\theta}>70000
\end{array}
$$


for local conditions at the OSV point. In these equations, $q^{\prime \prime}$ is the local heat flux, $k_{1}$ the fluid conductivity, and $P e=\frac{G D_{H} c_{p}}{k_{l}}=\operatorname{RePr}$ is the Peclet number. Combined with an energy balance, Eq. (7) allows the single-phase flow length $L_{l}$ to be calculated directly.

After the boundary is established between single-phase and two-phase flow at $L_{1 \phi}$, the shear terms must be dealt with. The single-phase flow can be readily modeled based on the Filonenko friction factor correlation and the Petukhov expression for the heat transfer coefficient that are currently used in the ANS Project [7]. Unfortunately analyzing the two-phase portion of the channel is not nearly as clear cut. A relatively simple drift flux model developed by Levy [4] was selected to predict the void fraction and twophase friction multiplier in this region. According to the Levy model, the mass fraction of vapor in the flow, $x^{\prime}(z)$, is related to the "true" thermodynamic quality $x(z)$ by

$$
x^{\prime}(z)=x(z)-x\left(L_{1 \phi}\right) \exp \left[\frac{x(z)}{x\left(L_{\phi}\right)}-1\right]
$$

where $x(z)=c_{p}\left[T(z)-T_{s a r}\left(P_{z}\right)\right] / h_{f g}\left(T_{s a t}\right)$ is determined from an energy balance. The associated void fraction in Levy's model, $\alpha(z)$, can then be found from

$$
\begin{aligned}
& \alpha(z)=x^{\prime}(z)\left[\frac{C_{0}\left(\rho_{1}-\rho_{v}\right)}{\rho_{l}} x^{\prime}(z)+\left[C_{0}+\frac{\overline{u_{g}}}{V_{l}}\right] \frac{\rho_{v}}{\rho_{l}}\right]^{-1} \\
& \text { where } C_{0}=1.13 \text { and } \overline{u_{\alpha}}=1.18\left[\frac{\sigma g\left(\rho_{1}-\rho_{v}\right)}{\rho_{l}^{2}}\right]^{1 / 4}
\end{aligned}
$$

Levy also gave the two-phase friction multiplier, $\phi^{2}$ as [8]

$$
\Phi^{2}=\frac{\left[1-x^{\prime}(z)\right]^{1.75}}{[1-\alpha(z)]^{2}}
$$

which represents the increase in wall shear relative to an equivalent single-phase flow. Hence

$$
-\left.\frac{d P}{d z}\right|_{\{, 2 \phi}=-\left.\frac{d P}{d z}\right|_{\{, 1 \phi} \phi^{2}
$$

where the frictional pressure drop, $\left.\frac{d P}{d z}\right|_{f, 1 \phi}$, for the single phase flow is determined using the Filonenko correlation discussed earlier.

One more correlation is still needed for integration of Eq. (6). To see how far the excursion should be allowed to proceed, one must have an expression predicting when CHF and the switch to film boiling in 
the channel will take place. The CHF correlation currently being used by the ANS Project is the Gambill/Weatherhead relation [7]:

$$
\begin{aligned}
& q_{C H F}^{\prime \prime}=h\left[T_{w}-T_{\text {buk }}\right]+0.18 h_{t \rho} \rho_{v}\left[\sigma g\left(\rho_{1}-\rho_{v}\right) / \rho_{v}^{2}\right]^{0.25} \\
& \times\left[1+\left(\rho_{1} / \rho_{v}\right)^{0.75} c_{\rho}\left(T_{\text {sat }}-T_{\text {bulk }}\right) /\left(9.8 h_{\text {to }}\right)\right] \\
& \text { and } T_{w}=\left[47.7-0.127 T_{\text {sat }}\right]\left(\frac{q_{C M F}^{\prime \prime}}{3154.6}\right)^{0.25}+T_{\text {sat }}
\end{aligned}
$$

where $q_{C H F}^{\prime \prime}$ is the critical heat flux, $h$ is the forced convection heat transfer coefficient predicted by Petukhov, and $T_{w}$ is the channel wall surface temperature. Since Eq. (12b) is a dimensional correlation, the heat flux needs to be expressed in kilowatts and all temperatures must be in Celsius for the results to be valid. The Gambill/Weatherhead equation can then be solved for $V_{i, C H P}$ the inlet flow velocity at which flow starvation causes a CHF failure at the channel exit.

To generate the solution of Eq. (6), a FORTRAN computer code called FLOWEXC has been written that employs 4th-order Runge-Kutta integration. The code FLOWEXC incorporates all the thermal hydraulic correlations already described, plus a set of relations compiled by Crabtree and Siman-Tov [9] to evaluate the thermophysical properties of light or heavy water as functions of temperature. Once $L_{l \downarrow}$ is obtained at each time step from an iterative algorithm based on the Saha-Zuber correlation, all components of the momentum equation are evaluated and a new inlet flow velocity is calculated. The flow excursion transient calculations continue until $V_{i}(t) \leq V_{i, C H F}$ from Gambill/Weatherhead. The fluid inertia delay for a flow excursion will be defined as the time between rounding the minimum of the demand curve, when the system first enters an unstable flow regime, and the point when FLOWEXC determines $V_{i, C H F}$ has been reached in the channel due to flow redistribution.

The transient code FLOWEXC was initially benchmarked by attempting to simulate a steady-state flow excursion experiment conducted in the thermal hydraulic test loop (THTL) here at the Oak Ridge National Laboratory. Designed to collect thermal-hydraulic data for the ANS, the THTL features prototypic heat fluxes and flow velocities comparable to those planned for the reactor [10]. Figures 4-6 show some results obtained using FLOWEXC to analyze THTL experiment FE331A, which had $T_{i}=45^{\circ} \mathrm{C}$, a constant heat flux of $12.2 \mathrm{MW} / \mathrm{m}^{2}$, and a fixed channel exit pressure of $1.7 \mathrm{MPa}$. An initial supply pressure perturbation of $0.05 \mathrm{MPa}$ below the demand curve minimum was imposed by reducing $P_{i}$ to $2.23 \mathrm{MPa}$ to bring about a flow excursion. The program FLOWEXC allows one to view the separate effects of single-phase friction, two-phase friction, and the acceleration momentum term on the overall demand curve. In Fig. 4 the individual components of the demand curve pressure drop are plotted versus velocity, which decreases with time throughout the transient. It is clear from the overall demand curve shown in Fig. 4 that the momentum term is the dominant factor influencing the shape of the demand curve to the left of the minimum point. In contrast to the rapid growth of the momentum term in two-phase flow, single-phase friction declined almost linearly throughout the transient, and two-phase friction was always relatively small. One should also note the change in slope predicted for the single-phase friction term at a velocity 
of about $17.9 \mathrm{~m} / \mathrm{s}$, which is due to reduction in $L_{1 \phi}$ once two-phase flow appears at the channel exit. In addition to the demand components, Fig. 4 contains a plot of the pressure defect curve during the excursion, which has the same shape as the overall demand curve shifted downward by the imposed supply pressure drop.

Figure 5 illustrates the contributions to the demand curve pressure drop of the single-phase and two-phase sections of the THTL channel. The single-phase contribution declined throughout the transient as the inlet flow velocity decreased. However this reduced pressure drop due to the single-phase flow was more than offset by an increasing pressure drop in the two-phase flow near the exit. Thus the pressure defect between supply and demand continues to increase, and the flow excursion proceeds at an accelerating pace as the two-phase flow section lengthens. The growing segment of the THTL channel that experiences two-phase flow is also evident in Fig. 6, which plots the ratios of single-phase flow length and incipient boiling location length to total channel length. For this calculation, FLOWEXC was modified to include the Bergles-Rohsenow correlation [11] for IB on the channel surface. Like RELAP5, FLOWEXC interprets the Saha-Zuber OSV point as the start of two-phase flow. Any multiphase effects between the IB and OSV points are neglected. For the THTL run simulated, the single-phase length ratio ranged from 1.0 down to 0.96 , and the IB location length ratio went from 0.70 to 0.63 .

Using the input data from THTL Case FE331A, FLOWEXC calculated an inertia delay time of $5.4 \mathrm{~ms}$ between rounding the demand curve minimum and $\mathrm{CHF}$. This is consistent with the FE331A test, which indicated a very rapid transient, but the THTL instrumentation is currently inadequate to measure a precise time value. The numerically-generated minimum of the demand curve also occurred at a flow velocity of about $17.75 \mathrm{~m} / \mathrm{s}$, quite close to the steady-state experimental value of $17.0 \mathrm{~m} / \mathrm{s}$. Thus the pressure drop and void fraction models included in FLOWEXC appear to fit the data relatively well. One other qualitative characteristic of flow excursions was also evident from simulating the THTL experiment: Most of the flow excursion time prior to CHF is spent near the minimum of the demand curve. Once the flow velocity in the channel becomes appreciably less than that corresponding to the local minimum in the pressure drop, the difference between the supply and demand increases rapidly until failure. Since this pressure defect provides the driving potential for flow excursion, the transient moves exceptionally quickly away from the minimum.

\section{Metastable Liquid Effects}

Another physical phenomenon that tends to impose a delay in flow excursion transients is the need to form a metastable, superheated liquid prior to nucleation of vapor bubbles. Clearly the onset of net vapor generation, which leads to flow excursion, cannot occur until sufficient superheat has built up for nucleation to begin. A key feature in any model for heterogeneous vapor nucleation is the size distribution of cavities available at the heated surface. For a particular cavity to be capable of nucleating vapor bubbles, the wall must have enough superheat for a bubble to satisfy the requirements of thermomechanical equilibrium. These equations generally predict a range of active cavity sizes that becomes narrower as the superheat declines. Below some threshold value of the superheat, the active cavity range goes to zero and no bubbles can be nucleated. Currently the ANS fuel plates are expected to have an average surface roughness of about $0.5 \times 10^{-6} \mathrm{~m}$, which gives some indication of the likely cavity size range. Thus sufficient superheat to initiate nucleation from cavities in this size range must be available prior to OSV.

Several models are available for predicting when cavities of any size are capable of becoming active nucleation sites. At present, the Bergles-Rohsenow correlation is being used in the ANS Project to 
indicate incipient boiling conditions [7]. Bergles and Rohsenow solved for the IB point by applying a graphical technique to the equations of thermomechanical equilibrium; hence this method is not suitable for calculating the range of active cavity sizes if the superheat is increased. However, the Hsu [12] and Davis-Anderson [13] models for incipient boiling can be manipulated to yield both criteria that a cavity must satisfy to become activated and predictions for the range of active cavity dimensions at higher wall superheats.

Since flow excursions can result from either reduction in the level of flow or from a shift in the demand curve at lower pressure, it is convenient to have two different forms of the IB criterion. When the supply pressure drop falls, the onset of nucleation will be due to rising $T_{w}$ as the flow is reduced while $P_{e}$ remains unchanged, so incipient boiling is best presented in terms of a minimum wall temperature for nucleation. Exit depressurization transients, on the other hand, have $T_{w}$ relatively constant, so the IB condition should be expressed as the value of $P_{c}$ (or $T_{\text {sat }}$ at the exit) above which nucleation is impossible. Using DavisAnderson, the required equations are

$$
T_{w, \min }=T_{s a t}+\left[\frac{8 \sigma T_{s a t} q_{w}^{\prime \prime}}{k_{1} h_{f g} \rho_{v}}\right]^{1 / 2}
$$

or

$$
T_{s a t \max }=T_{w}+\frac{4 q_{w}^{\prime \prime} \sigma}{k_{1} h_{f g} \rho_{v}}-\left[\frac{8 q_{w}^{\prime \prime} \sigma}{k_{1} h_{f g} \rho_{v}}\left(T_{w}+\frac{2 q_{w}^{\prime \prime} \sigma}{k_{1} h_{f g} \rho_{v}}\right)\right]^{1 / 2}
$$

and the cavity size range that is active at higher superheats is given by

$$
r_{c}=\frac{1}{2}\left[\frac{\left(T_{w}-T_{s a t}\right) k_{l}}{q_{w}^{\prime \prime}} \pm\left[\left(\frac{\left(T_{w}-T_{s a t}\right) k_{l}}{q_{w}^{\prime \prime}}\right)^{2}-\frac{8 \sigma k_{l} T_{s a t}}{h_{f g} \rho_{v} q_{w}^{\prime \prime}}\right]^{1 / 2}\right]
$$

Hsu's model yields the analogous formulas

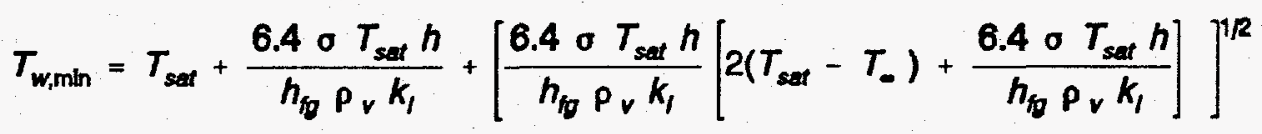

or

$$
T_{\text {sat } \max }=T_{w}+\frac{6.4 \sigma h\left(T_{w}-T_{-}\right)}{k_{1} h_{t o} P_{v}}-\left[\frac{12.8 \sigma h\left(T_{w}-T_{-}\right)}{k_{1} h_{10} P_{v}}\left[T_{w}+\frac{3.2 \sigma h\left(T_{w}-T_{-}\right)}{k_{1} h_{6 q} P_{v}}\right]\right]^{1 / 2}
$$

for the IB requirements and 


$$
r_{c}=\frac{k_{1}}{4 h}\left[\left(1-\frac{T_{\text {sat }}-T_{-}}{T_{w}-T_{-}}\right) \pm\left[\left(1-\frac{T_{\text {sat }}-T_{-}}{T_{w}-T_{-}}\right)^{2}-\frac{12.8 \sigma T_{\text {sat }} h}{\rho_{v} h_{\text {to }} k_{l}\left(T_{w}-T_{-}\right)}\right]^{1 / 2}\right]
$$

for the active cavity size range. The primary difference between the two models arises because of slight variations in the assumed shape of the embryo bubble. These equations will be used to test the thermalhydraulic conditions predicted by FLOWEXC at IB and OSV to see whether enough wall superheat is available for activation of cavities in the expected ANS size range. If metastable liquid effects can delay the nucleation of vapor bubbles past the expected OSV point, then the time scale for flow excursion must be lengthened accordingly until more superheat can develop.

\section{Plate Thermal Inertia Delay}

The last phase of a flow excursion transient will involve heat-up of the fuel plates toward the melting point as a result of inadequate cooling near the channel exit. Weatherhead's correlation for $T_{w}$ [Eq. (12b)] allows one to calculate the minimum temperature needed for $\mathrm{CHF}$ at the exit. Once this wall temperature has been exceeded, rewetting is no longer possible, and fuel damage becomes unavoidable unless the exit pressure increases significantly. To obtain a conservative initial estimate of the role of thermal inertia, the adiabatic heating rate, $\frac{d T}{d t}$, for a fuel plate can be determined from the equation

$$
\left(m_{\text {fuel }} c_{p, \text { fuer }}+m_{\text {cladding }} c_{p, \text { dadding }}\right) \frac{d T}{d t}=\dot{E}_{\text {gen }}
$$

where $\dot{E}_{g e n}$ is internal heat generation rate within the plate. Thus it is possible to obtain a characteristic minimum time required for heat release inside a fuel plate to bring about any temperature increase necessary for CHF to take place.

\section{COMPARISON WITH RELAP5 MOD3 RESULTS}

Three RELAP5 flow excursion cases in the ANS geometry were selected for analysis using the transient models developed in the preceding section. Both declining core flow and core exit depressurization scenarios have been examined, with all calculations starting from full ANS power levels. In the first RELAP case, the supply pressure drop across a flow channel was ramped linearly from its nominal value down to zero over a period of 100 seconds to start the excursion, while the inlet pressure remained fixed. Another simulation involved reducing the channel exit pressure linearly to atmospheric over a period of 100 seconds with flow rate held constant. The first of these cases corresponds to a flow excursion generated by movement down the channel demand curve to the minimum point, and the second simulates an excursion resulting from an upward shift of the demand curve at lower pressures. The last case analyzed consisted of the 127-mm PSVAW break scenario discussed in connection with Fig. 2, where flow excursion limits were briefly exceeded. To reproduce the channel flow characteristics indicated by RELAP5, the channel inlet and exit pressures as transient functions of time were extracted from the 
RELAP run and submitted to FLOWEXC as boundary conditions. Figure 7 shows these pressure histories, with the sharp minima that caused the Costa limit to be exceeded at $8.8 \mathrm{~ms}$ and $32.5 \mathrm{~ms}$ clearly evident.

For all three of these transient cases, the first stage of flow excursion involves the nucleation and growth of vapor bubbles to detachment size. Table 1 summarizes the results of applying the bubble growth models developed earlier at the Saha-Zuber OSV conditions for each case. The calculated bubble radius at detachment from the wall ranged from $4.73 \times 10^{-6} \mathrm{~m}$ for the PSVAW break simulation up to $8.97 \times$ $10^{-6} \mathrm{~m}$ for the declining flow transient, leading to growth times between 0.421 and 1.76 microseconds. Longer times were associated with the declining flow case because the more subcooled exit conditions slowed bubble growth, and the bubbles also had to be larger before the reduced flow velocity could strip them off the wall. However the flow excursion delay due to bubble nucleation and growth appears to be insignificant under conditions typical of the ANS.

The inertia delays for the reduced-flow and loss-of-exit-pressure scenarios allow the most direct comparisons between the transient models developed in this paper and those from RELAP5. To estimate the fluid inertia time scale for a flow excursion, one must plot the demand curve reconstructed by either RELAP or FLOWEXC and then measure the elapsed time between the minimum point and critical heat flux conditions. Figures 8 and 9 illustrate the demand curves output by RELAP5 for one nodalization of each case. In Fig. 8, 50 nodes were used axially along the ANS channel to do the declining flow transient, while Fig. 9 presents the demand curve for an exit depressurization based on 95 axial nodes. Both sets of calculations were done using FLOWEXC as well as several different RELAP5 nodalizations, and the results are given in Table 2. All the reduced-flow transients exhibited a negatively sloped demand pressure drop prior to the onset of flow instability at the minimum point, while OSV had already occurred somewhat earlier in the transient. On the other hand, the exit depressurization situations started out from a fixed flow rate and channel pressure drop until the instability. Here OSV essentially coincided with the minimum point because the formation of vapor is due to virtually instantaneous flashing at low pressure.

Examination of Table 2 shows several interesting features of these transients. Clearly a fine axial nodalization is very important to model such problems with RELAP. For both decreasing flow and core exit depressurization situations, the calculated inertia delay decreased significantly as the original 5-node model was refined. The transient time needed to bring about OSV was also reduced with each finer nodalization. This earlier appearance of OSV is easily understood when one remembers that RELAP5 only calculates pressures at cell centers. A finer node spacing means the center of the last cell will be closer in pressure to the exit plenum; thus less reduction in $P_{e}$ is necessary to bring this cell to OSV conditions. Predicted inertia delays for the declining flow transient ranged from 0.33 to $0.38 \mathrm{~s}$ with the fine-nodalization RELAP runs. These numbers compare reasonably well with the $0.16 \mathrm{~s}$ estimate obtained from FLOWEXC. For the exit depressurization simulations, the shortest inertial time scale calculated with RELAP was $8.3 \mathrm{~s}$, which is much longer than the FLOWEXC value of $0.4 \mathrm{~ms}$. This discrepancy apparently reflects different models for the strength of vapor generation in the two codes. However most of the experimental evidence available points to times much closer to the FLOWEXC value for depressurization flow excursions [14].

No attempt was made to plot the demand curves generated by RELAP and FLOWEXC when simulating the 127-mm PSVAW break because they would have been distorted by the rapid pressure variations. Instead, the main question in this case was simply whether the fluid inertia provided sufficient delay for the system to "ride over" the depressurization spikes at $t=8.8 \mathrm{~ms}$ and $32.5 \mathrm{~ms}$ without experiencing a flow excursion, even though the Costa condition was violated. The RELAP5 run indicated no OSV or flow excursion under these conditions. On the other hand FLOWEXC experienced OSV $8.0 \mathrm{~ms}$ into the 
transient and suffered a CHF failure at $\mathrm{t}=8.2 \mathrm{~ms}$, before $P_{e}$ even reached its first minimum value. This situation probably reflects the same difference between the two codes that was evident with the earlier depressurization transient. It should be noted that in the PSVAW break calculations, FLOWEXC used a set of ANS hot stripe heat fluxes for flow excursion to evaluate the coolant bulk temperature rise as well as in calculations to determine thermal limits. Such a procedure is somewhat different from that used in RELAP5 and would tend to make the transient more severe.

Table 3 contains the results from applying the Hsu and Davis-Anderson models for incipient boiling to the reduced flow transient, the core exit depressurization, and the PSVAW break simulation. With the reduced flow transient, the $\mathrm{IB}$ condition is presented in terms of a minimum wall temperature for nucleation, while the two depressurization cases express it in terms of a maximum exit pressure. Both models indicate IB would occur later than predicted by Bergles-Rohsenow, but the nucleation criteria were always satisfied prior to the Saha-Zuber OSV point except for the Hsu model analysis of the exit depressurization run. Furthermore, the active cavity range predictions of both models under OSV conditions nicely span the average surface roughness expected with ANS fuel plates for either reduced flow or the PSVAW break situation. For exit depressurization at OSV, the Davis-Anderson active cavity span was slightly larger than the mean ANS roughness but in the same general size range, while the Hsu nucleation criterion was not quite satisfied. In general, it appears metastable liquid effects may delay incipient boiling somewhat, but IB is unlikely to be extended past the OSV point enough to inhibit a flow excursion during any of the three transients studied.

The last time scale for flow excursion in the ANS is that resulting from the thermal inertia of the fuel plates themselves. Results of these calculations for all three test cases are included in Table 4. The table shows the initial wall temperature corresponding to single-phase convection at the channel exit for each case, and gives the minimum wall temperature necessary for CHF at the exist as calculated from Weatherhead's correlation using the thermal-hydraulic conditions at the end of the FLOWEXC transient. Once the plate adiabatic heating rate has been determined, it is then possible to estimate the minimum time needed to reach CHF. As seen in Table 4, the CHF wall temperatures at failure for both exit depressurization and the PSVAW break run are slightly less than the corresponding initial wall temperatures. This fact reflects the drop in $T_{C H F}$ as the exit pressure falls during the transient. No thermal inertia delay seems to be available under such conditions. For the reduced flow case, a minimum delay of $9.01 \mathrm{~ms}$ is necessary to reach $T_{C H F}$, but this characteristic time is still much shorter than the $0.160 \mathrm{~s}$ time already predicted by FLOWEXC for fluid inertial delay. Apparently adiabatic thermal inertia effects can do little to extend the flow excursion times calculated from mechanical inertia of the coolant in the ANS reactor core.

All the analysis performed so far to supplement RELAP5 runs for the ANS Project has emphasized the speed of flow excursion transients under the thermal-hydraulic conditions present in the ANS core. At present, it does not appear that the ANS conceptual design can survive the acoustic waves resulting from an instantaneous pipe break without suffering some fuel damage due to flow excursion. Work continues on refining the transient models developed for each stage of a flow excursion and improving the agreement with complementary RELAP5 simulations. It is also planned to carry out some transient experiments here at ORNL, so that each stage of flow excursion can be observed in real time. Hopefully this work will lead to increased understanding of flow excursion transients and how they would progress during accident scenarios in the ANS reactor or any system involving similar geometry and power densities. 


\section{CONCLUSIONS}

1. Time scales for flow excursion transients can be obtained by separating the transient into its component phenomena and modeling them individually.

2. The inertia effects required to decelerate the coolant flow apparently provide the dominant time scale during a flow excursion. As a result, most of the transient prior to fuel damage is spent near the minimum in the demand curve.

3. Thermal inertia effects are most evident in reduced flow transients, while the influence of a metastable liquid phase is largely confined to depressurization cases. However neither effect adds appreciably to the fluid inertia delay.

4. A fine axial nodalization is necessary to obtain a realistic flow excursion simulation in RELAP5. Even so, RELAP's vapor generation rate seems too slow for exit depressurization cases.

5. For high performance, parallel-channel reactors like the ANS, flow excursion time scales are often in the millisecond range, especially when the exit plenum pressure drops suddenly. Apparently even a very brief excursion scenario might lead to fuel damage.

\section{ACKNOWLEDGEMENT}

This paper is based on research supported by the ANS Project office at ORNL. The assistance of Lara James, David Morris, Moshe Siman-Tov, Grady Yoder, and other contributors who helped make the work possible is greatly appreciated.

\section{REFERENCES}

1. M. Ledinegg, "Instability of Flow During Natural and Forced Circulation," Die Warme, 61, 891-898 (1938).

2. J. Costa, "Measurement of the Momentum Pressure Drop and Study of the Appearance of Vapor and Change in the Void Fraction in Subcooled Boiling at Low Pressure," Proc. of Meeting of the European Group Double-Phase, Winfrith (1967). Translated from French as ORNL/TR-90/21.

3. G. L. Yoder, et al., "ANS Transient Thermal Hydraulic Task Monthly Progress Report for December 1993," Memo to R. M. Harrington and K. F. Rosenbalm of ORNL (1994).

4. S. Levy, "Forced Convection Subcooled Boiling - Prediction of Vapor Volumetric Fraction," Int. J. Heat and Mass Transfer, 10, $951-965$ (1967).

5. B. B. Mikic, W. M. Rohsenow, and P. Griffith, "On Bubble Growth Rates," Int. J. Heat and Mass Transfer, 13, 657-666 (1970).

6. P. Saha and N. Zuber, "Point of Net Vapor Generation and Vapor Void Fraction in Subcooled Boiling," Proc. 5th Int. Heat Transfer Conference, Tokyo, 4, 175-179 (1974). 
7. M. Siman-Tov, W. R. Gambill, W. R. Nelson, A. E. Ruggles and G. L. Yoder, "Thermal-Hydraulic Correlations for the Advanced Neutron Source Reactor Fuel Element Design and Analysis," Proc. 1991 ASME Winter Annual Meeting, Atlanta (1991).

8. J. G. Collier, Convective Boiling and Condensation, McGraw Hill, New York (1981).

9. A. Crabtree and M. Siman-Tov, "Thermophysical Properties of Saturated Light and Heavy Water for Advanced Neutron Source Applications," ORNL/TM-12322 (1993).

10. D. K. Felde, et al., "Advanced Neutron Source Reactor Thermal-Hydraulic Test Loop Facility Description," ORNL/TM-12397 (1994).

11. A. E. Bergles and W. M. Rohsenow, "The Determination of Forced-Convection Surface-Boiling Heat Transfer," ASME J. of Heat Transfer, 86, 365-372 (1964).

12. Y. Y. Hsu, "On the Size Range of Active Nucleation Cavities on a Heating Surface," ASME J. of Heat Transfer, 84, 207-213 (1962).

13. E. J. Davis and G. H. Anderson, "The Incipience of Nucleate Boiling in Forced Convection Flow," AIChE J., 12, 4, 774-780 (1966).

14. C. A. Wemple, et al., "Advanced Neutron Source Idaho National Engineering Laboratory Monthly Report for January 1993," Memo to D. L. Selby of ORNL (1993).

\section{DISCLAIMER}

This report was prepared as an account of work sponsored by an agency of the United States Government. Neither the United States Government nor any agency thereof, nor any of their employees, makes any warranty, express or implied, or assumes any legal liability or responsibility for the accuracy, completeness, or usefulness of any information, apparatus, product, or process disclosed, or represents that its use would not infringe privately owned rights. Reference herein to any specific commercial product, process, or service by trade name, trademark, manufacturer, or otherwise does not necessarily constitute or imply its endorsement, recommendation, or favoring by the United States Government or any agency thereof. The views and opinions of authors expressed herein do not necessarily state or reflect those of the United States Government or any agency thereof. 
Table 1. Summary of bubble growth times to detachment

\begin{tabular}{|c|c|c|c|c|}
\hline & $\begin{array}{c}\text { Normalized } \\
\text { detachment } \\
\text { radius }\end{array}$ & $\begin{array}{c}\text { Actual radius at } \\
\text { detachment } \\
(\mu \mathrm{m})\end{array}$ & $\begin{array}{c}\text { Normalized } \\
\text { bubble growth } \\
\text { time }\end{array}$ & $\begin{array}{c}\text { Actual bubble } \\
\text { growth time } \\
(\mu \mathrm{s})\end{array}$ \\
\hline $\begin{array}{c}\text { Declining flow } \\
\text { transient case }\end{array}$ & 29.27 & 8.973 & 10.512 & 1.76 \\
\hline $\begin{array}{c}\text { Exit } \\
\text { depressurization } \\
\text { case }\end{array}$ & 22.39 & 4.780 & 0.0719 & 0.62 \\
\hline $\begin{array}{c}\text { 127-mm } \\
\text { PSVAW break } \\
\text { case (hot-stripe } \\
\text { heat fluxes) }\end{array}$ & 23.68 & 4.729 & 0.0622 & 0.42 \\
\hline
\end{tabular}

Table 2. Fluid inertia delays for declining flow and exit depressurization

\begin{tabular}{|c|c|c|c|c|}
\hline & Model adopted & $\begin{array}{c}\text { Transient time to } \\
\text { OSV } \\
\text { (s) }\end{array}$ & $\begin{array}{l}\text { Transient time to } \\
\text { demand curve } \\
\text { minimum } \\
\text { (s) }\end{array}$ & $\begin{array}{l}\text { Inertia delay } \\
\text { time beyond } \\
\text { minimum point } \\
\text { (s) }\end{array}$ \\
\hline \multirow{4}{*}{$\begin{array}{l}\text { Declining flow } \\
\text { transient case }\end{array}$} & RELAP 5-cell & 29.0 & 29.85 & 1.0 \\
\hline & RELAP 20-cell & 27.10 & 29.63 & 0.33 \\
\hline & RELAP 50-cell & 27.05 & 29.45 & 0.38 \\
\hline & FLOWEXC & - & 一 & 0.16 \\
\hline \multirow{4}{*}{$\begin{array}{l}\text { Declining core } \\
\text { exit pressure } \\
\text { case }\end{array}$} & RELAP 5-cell & 66.7 & 66.7 & 19.3 \\
\hline & RELAP 20-cell & 59.3 & 59.3 & 9.7 \\
\hline & RELAP 95-cell & 57.4 & 57.4 & 8.3 \\
\hline & FLOWEXC & - & - & 0.0004 \\
\hline
\end{tabular}


Table 3. Summary of activated cavity size ranges at OSV

\begin{tabular}{|c|c|c|c|c|}
\hline & \multicolumn{2}{|c|}{ Nucleation condition needed for $\mathrm{IB}$} & \multicolumn{2}{|c|}{ Cavity radius range at OSV } \\
\cline { 2 - 5 } & Hsu model & $\begin{array}{c}\text { Davis-Anderson } \\
\text { model }\end{array}$ & Hsu model & $\begin{array}{c}\text { Davis- } \\
\text { Anderson } \\
\text { model }\end{array}$ \\
\hline $\begin{array}{c}\text { Declining flow case } \\
\text { moxs }\end{array}$ & $\mathrm{T}_{\mathrm{w}}>225.5^{\circ} \mathrm{C}$ & $\mathrm{T}_{\mathrm{w}}>219.1^{\circ} \mathrm{C}$ & $\begin{array}{c}7.600 \times 10^{-8} \mathrm{~m} \\
\text { to } \\
1.533 \times 10^{-6} \mathrm{~m}\end{array}$ & $\begin{array}{c}9.321 \times 10^{-8} \mathrm{~m} \\
\text { to } \\
3.125 \times 10^{-6} \mathrm{~m}\end{array}$ \\
\hline $\begin{array}{c}\text { Exit depressurization } \\
\text { case }\end{array}$ & $\mathrm{P}_{\mathrm{e}}<0.291 \mathrm{MPa}$ & $\mathrm{P}_{\mathrm{e}}<0.348 \mathrm{MPa}$ & - & $\begin{array}{c}7.741 \times 10^{-7} \mathrm{~m} \\
\text { to } \\
1.830 \times 10^{-6} \mathrm{~m}\end{array}$ \\
\hline $\begin{array}{c}127 \text {-mm PSVAW } \\
\text { Break Case (hot-stripe } \\
\text { heat fluxes) }\end{array}$ & $\mathrm{P}_{\mathrm{e}}<0.539 \mathrm{MPa}$ & $\mathrm{P}_{\mathrm{e}}<0.649 \mathrm{MPa}$ & $\begin{array}{c}2.526 \times 10^{-7} \mathrm{~m} \\
\text { to }\end{array}$ & $\begin{array}{c}2.867 \times 10^{-7} \mathrm{~m} \\
\text { to }\end{array}$ \\
\hline
\end{tabular}

Table 4. Summary of fuel plate thermal inertia effects

\begin{tabular}{|c|c|c|c|c|}
\hline & $\begin{array}{c}\text { Initial wall } \\
\text { temp. } \\
\left({ }^{\circ} \mathrm{C}\right)\end{array}$ & $\begin{array}{c}\mathrm{CHF} \text { wall temp. } \\
\left({ }^{\circ} \mathrm{C}\right)\end{array}$ & $\begin{array}{c}\text { Adiabatic } \\
\text { heating rate } \\
\left({ }^{\circ} \mathrm{C} / \mathrm{s}\right)\end{array}$ & $\begin{array}{c}\text { Minimum } \\
\text { heating time } \\
(\mathrm{ms})\end{array}$ \\
\hline Declining flow case & 164.5 & 228.8 & 7138 & 9.01 \\
\hline $\begin{array}{c}\text { Exit depressurization } \\
\text { case }\end{array}$ & 164.5 & 161.1 & 7264 & - \\
\hline $\begin{array}{c}127 \text { mm PSVAW break } \\
\text { case (hot-stripe heat } \\
\text { fluxes) }\end{array}$ & 186.6 & 181.0 & 7451 & - \\
\hline
\end{tabular}




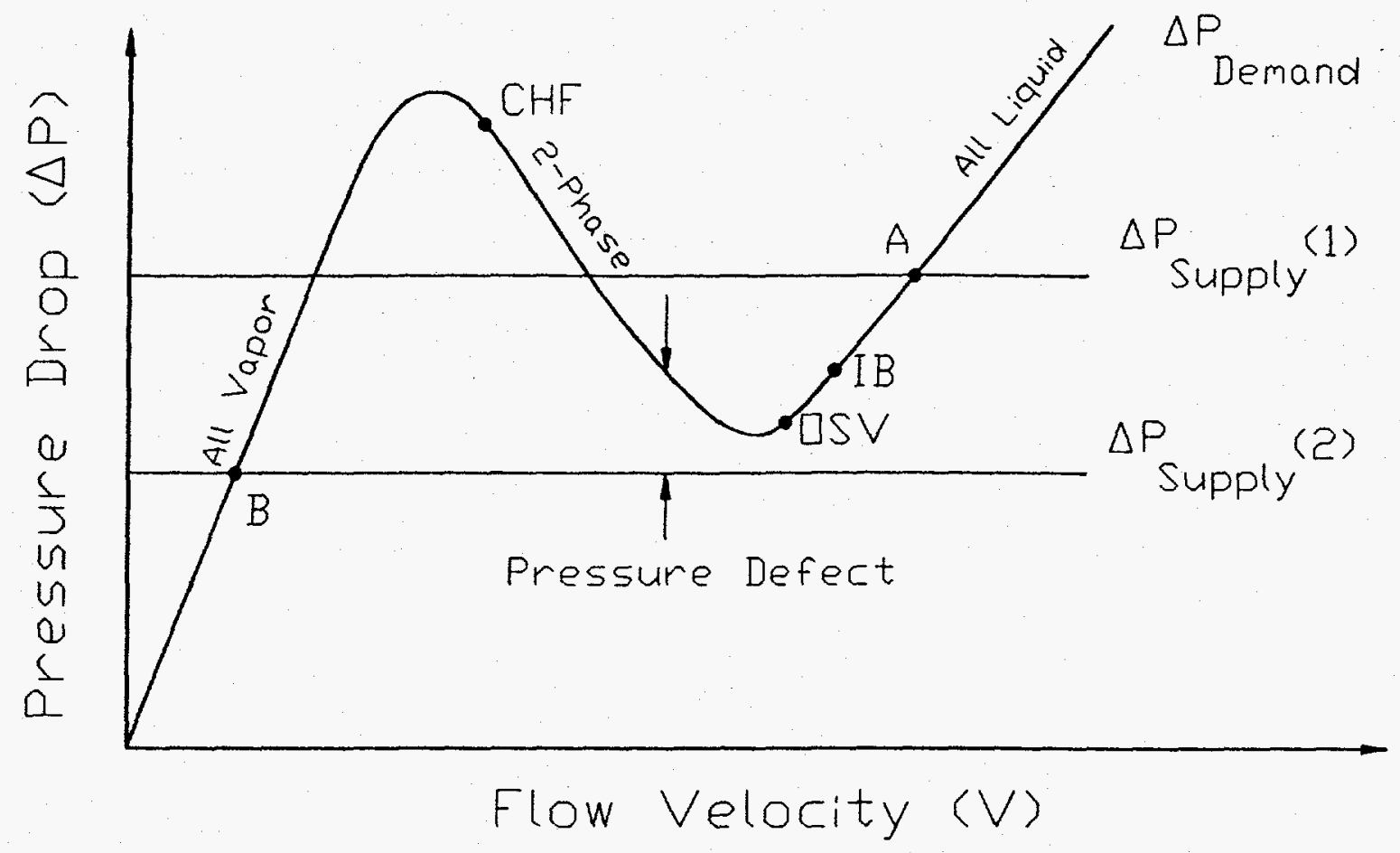

Fig. 1. Supply and demand curves showing the mechanism of flow excursion in a system of parallel channels. 


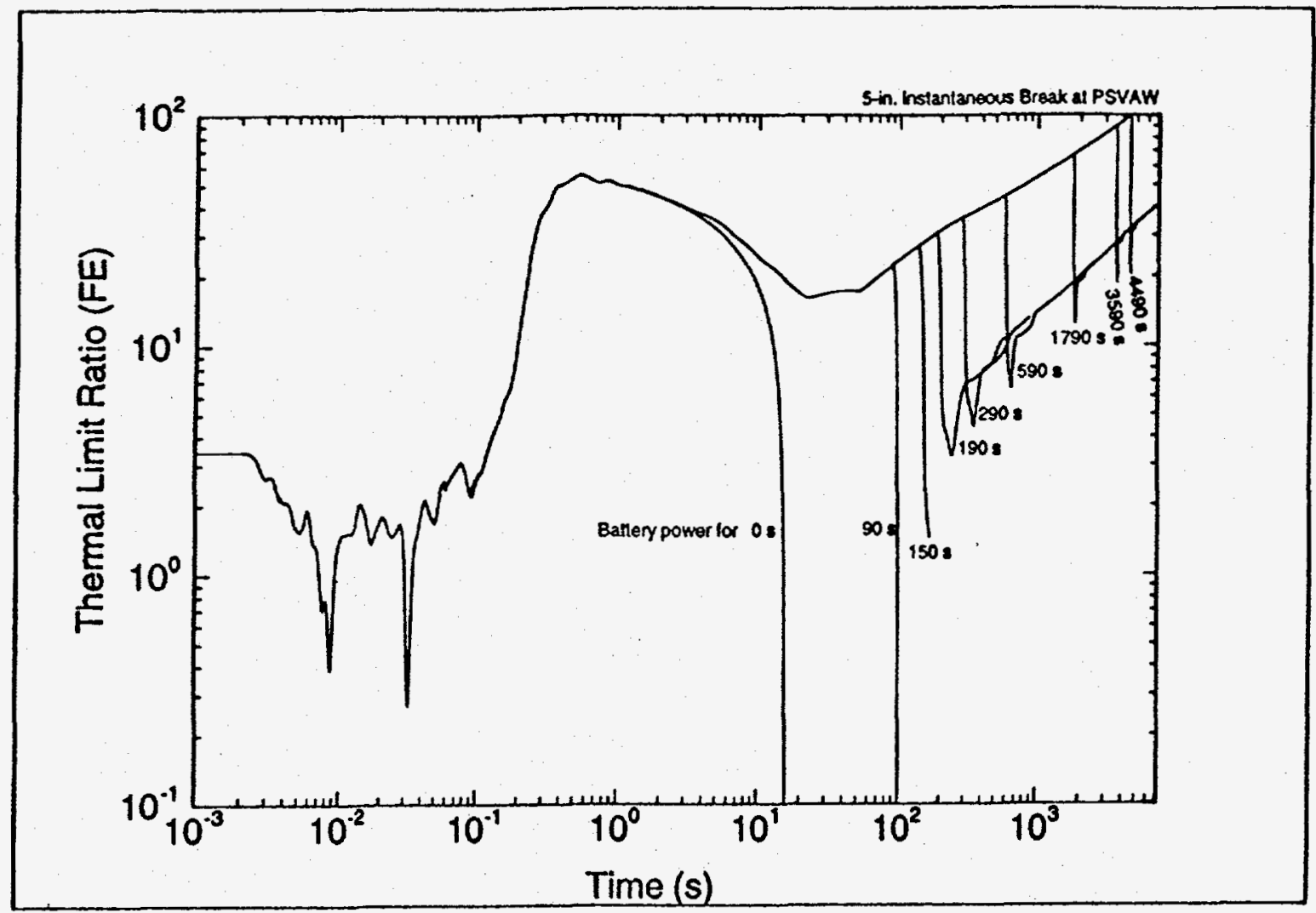

Fig. 2. Flow excursion thermal limit ratio for various battery lifetimes during an instantaneous 127 $\mathrm{mm}$ break at the PSVAW. 


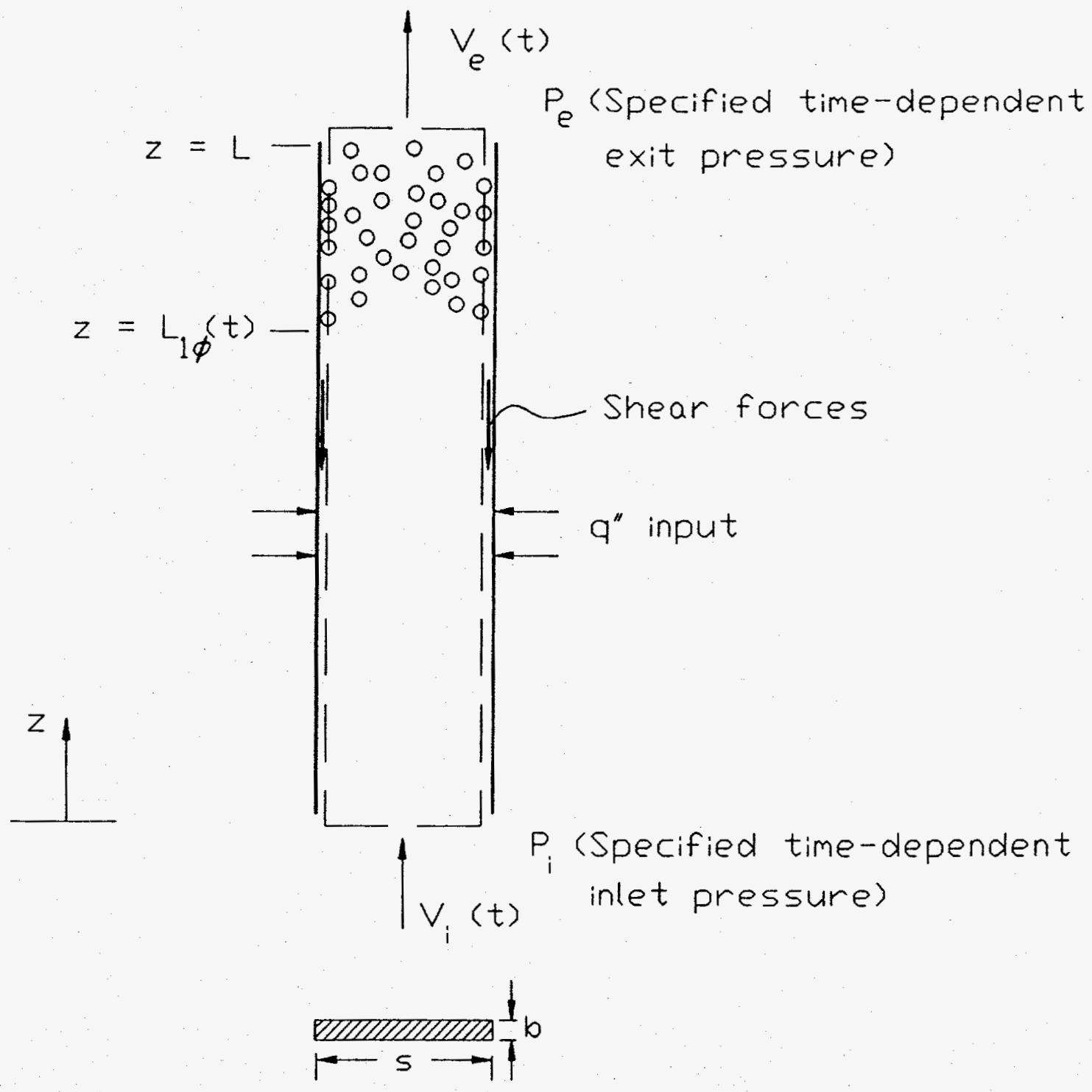

Fig. 3. Schematic of an ANS coolant channel for applying the integral momentum equation. 


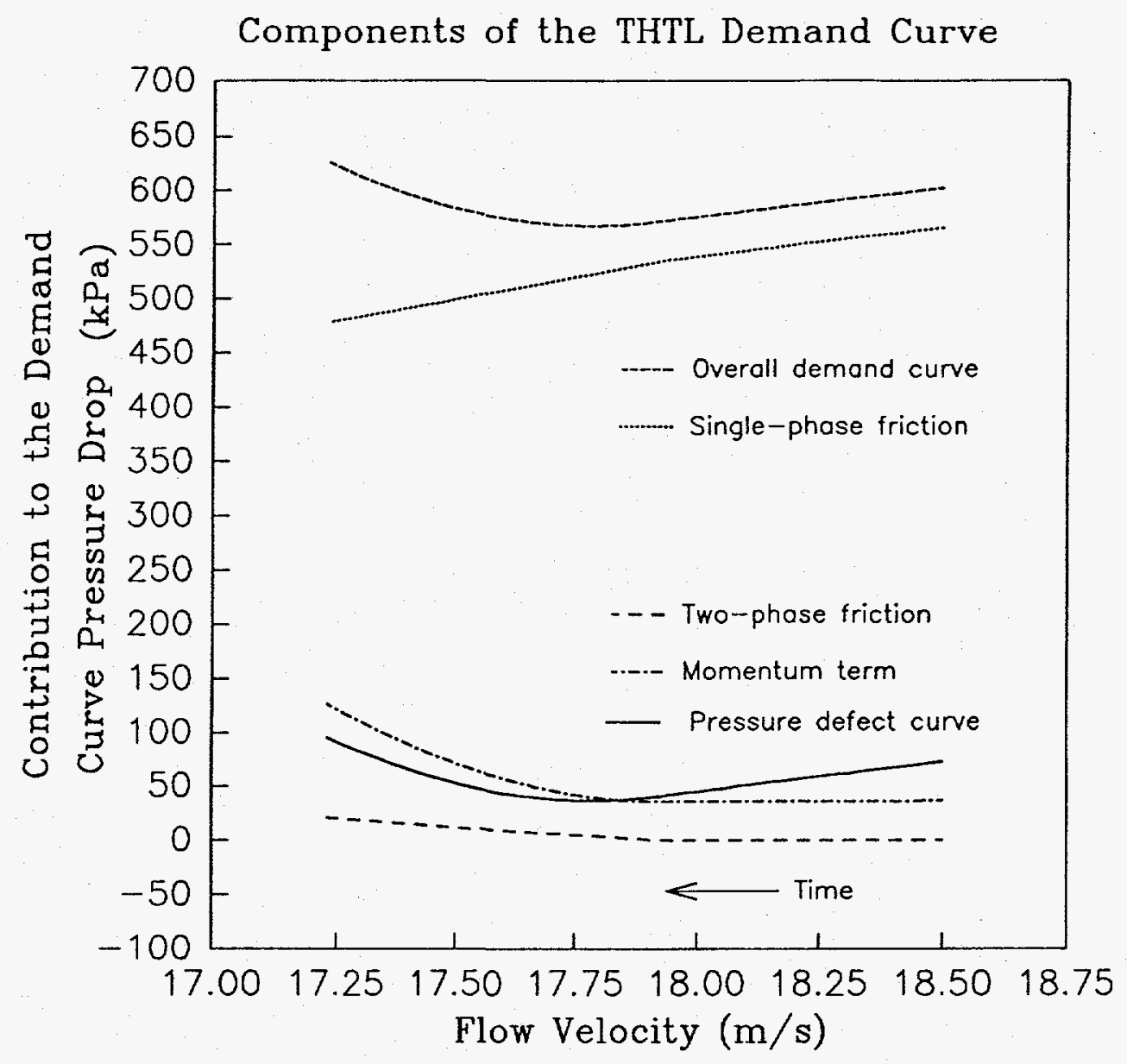

Fig. 4. Contribution of the individual force components to the overall demand curve for flow excursion test FE331A in the THTL. 


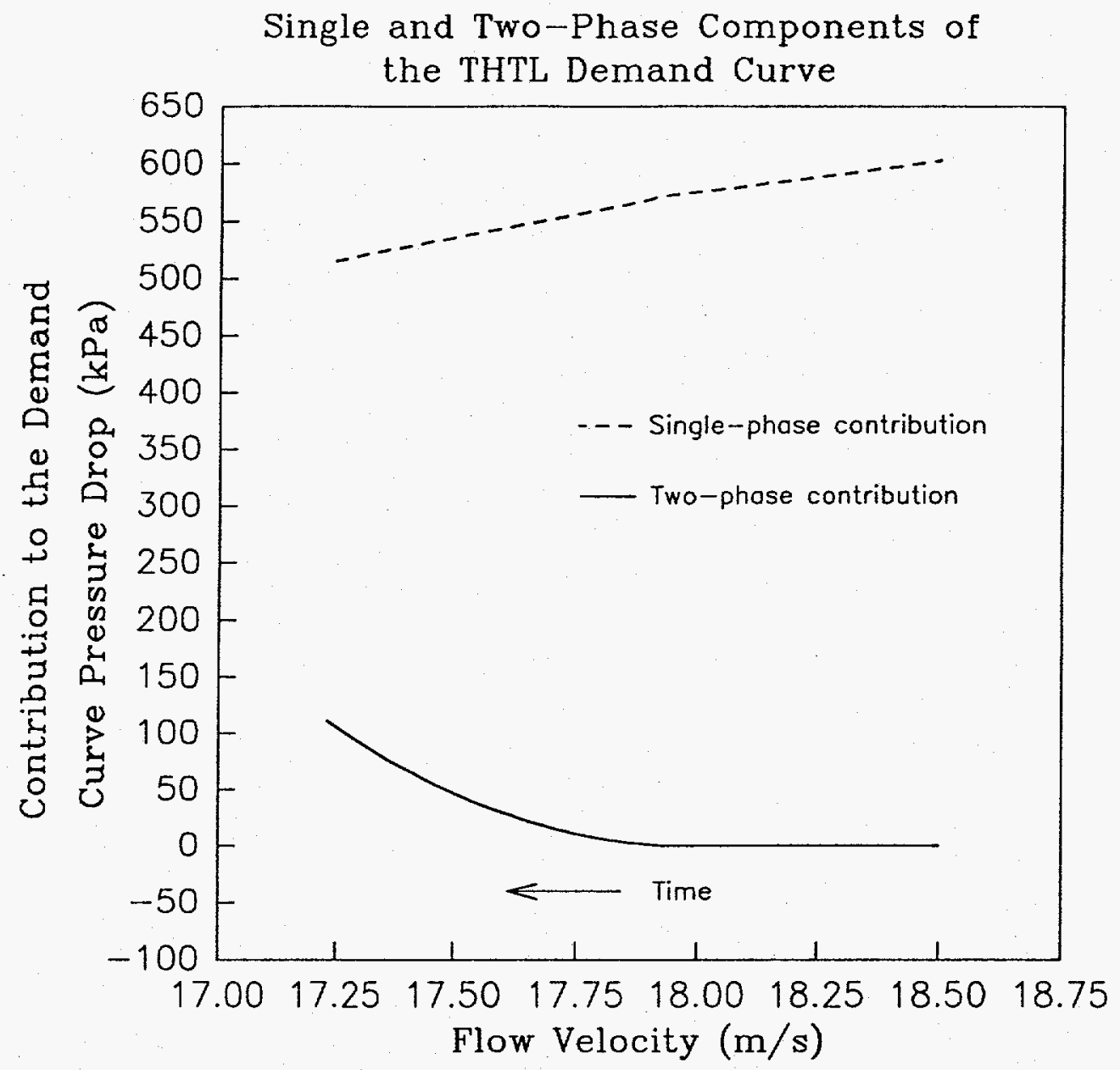

Fig. 5. Single-phase flow and two-phase flow contributions to the overall demand curve during an excursion in the THTL. 


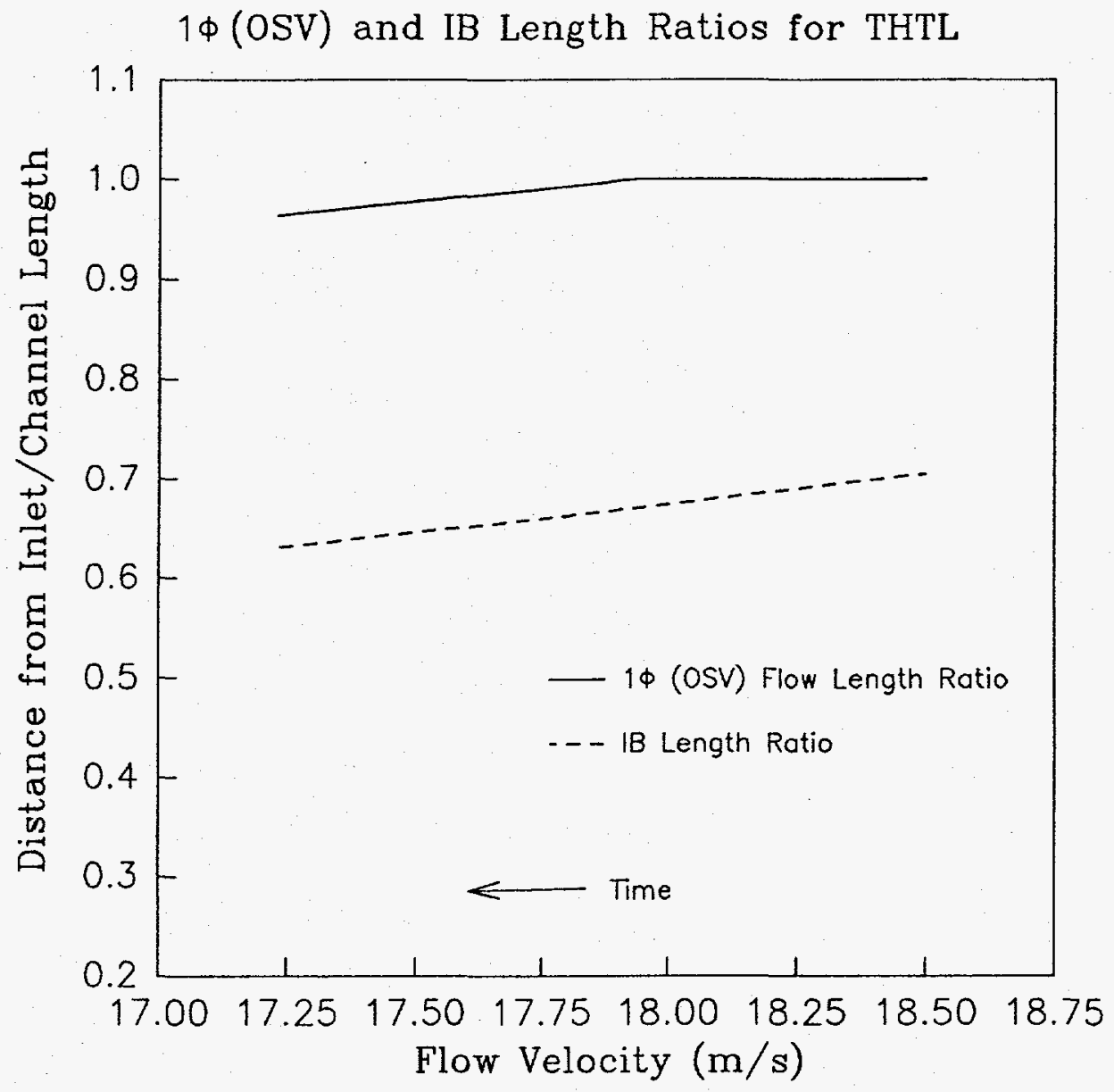

Fig. 6. Single-phase flow and incipient boiling length ratios for a flow excursion in the THTL. 


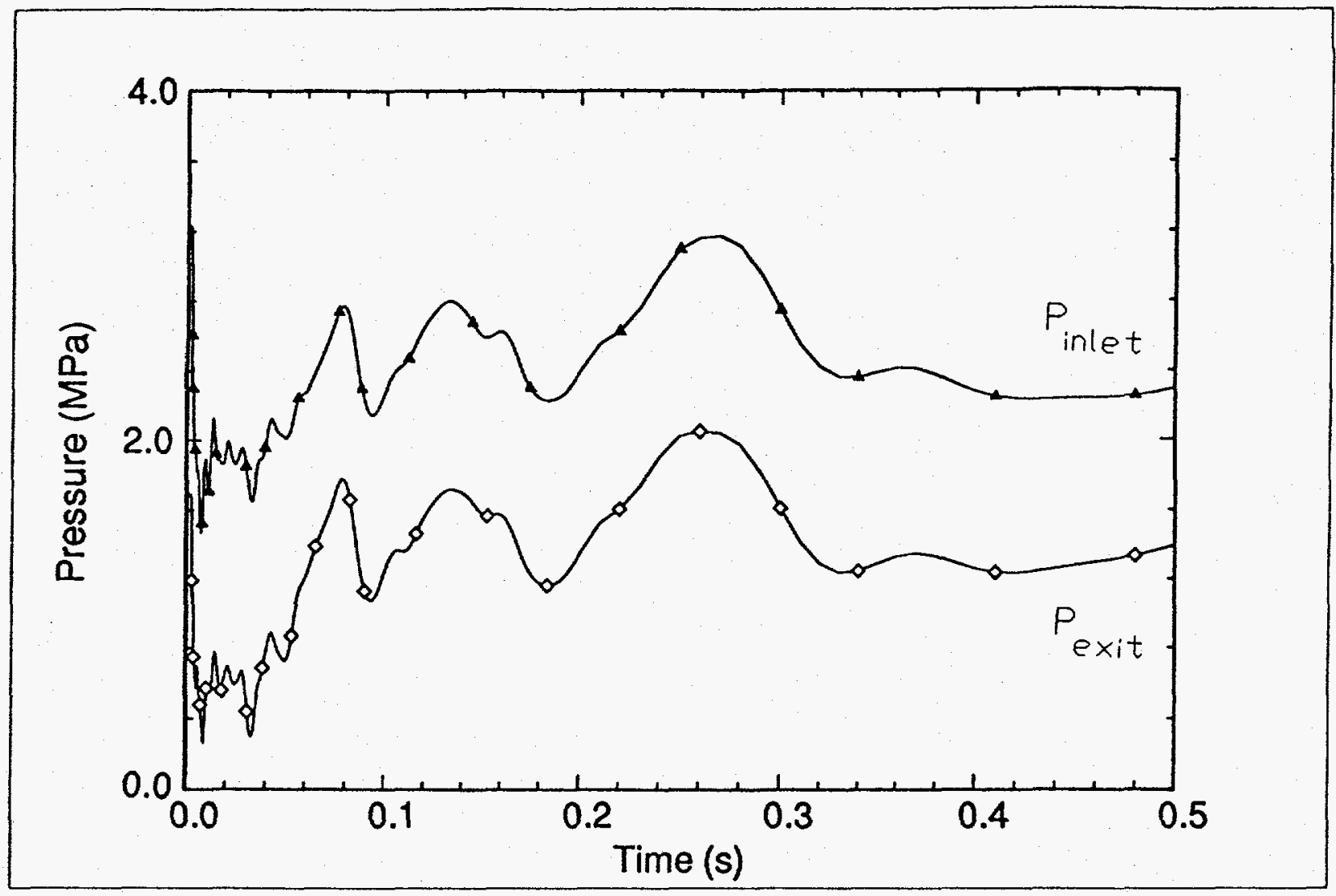

Fig. 7. Transient histories of the channel inlet and exit pressures used as FLOWEXC boundary conditions for the PSVAW break case. 


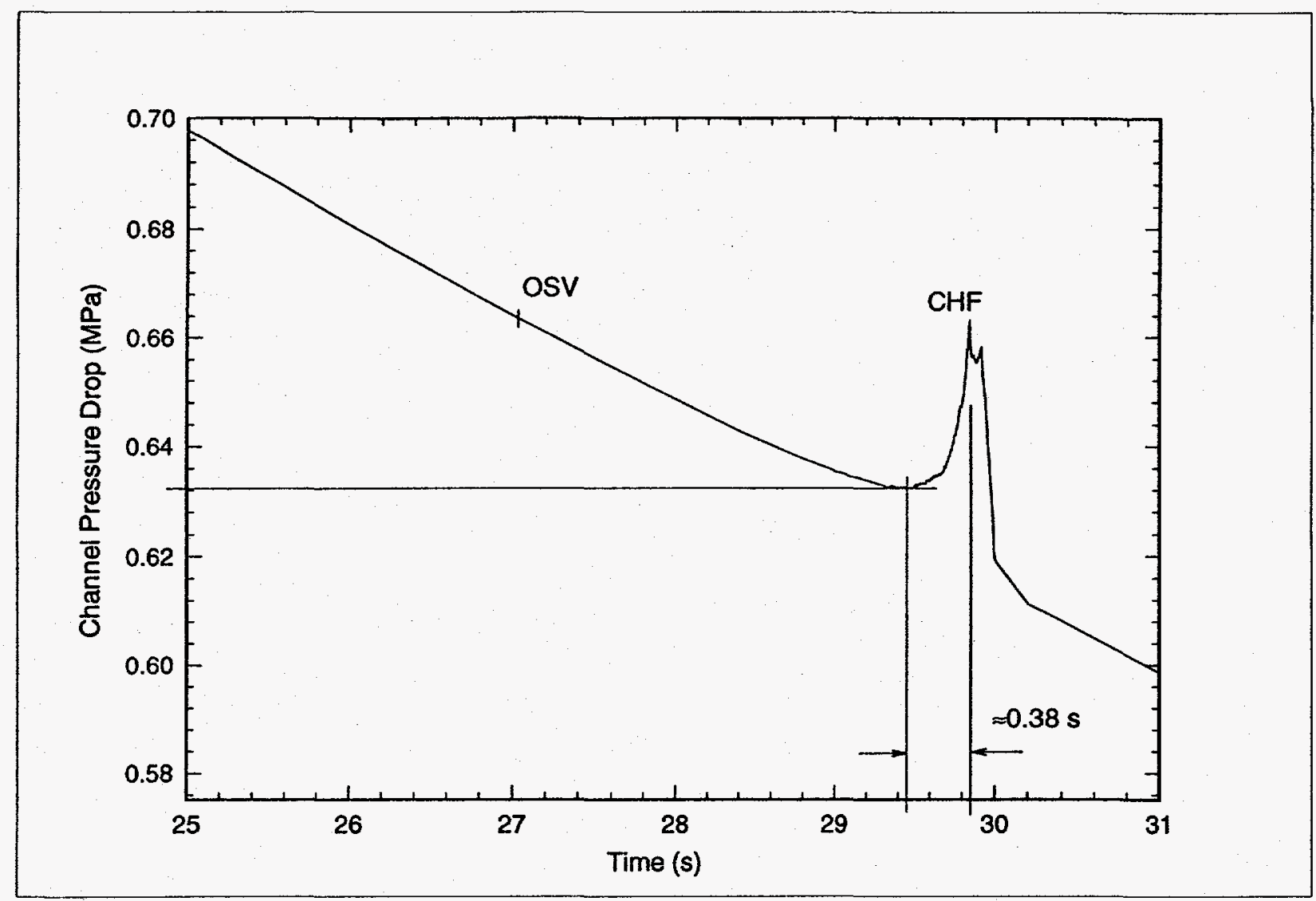

Fig. 8. Channel demand pressure drop for the reduced flow transient case using 50 axial nodes in RELAP5. 


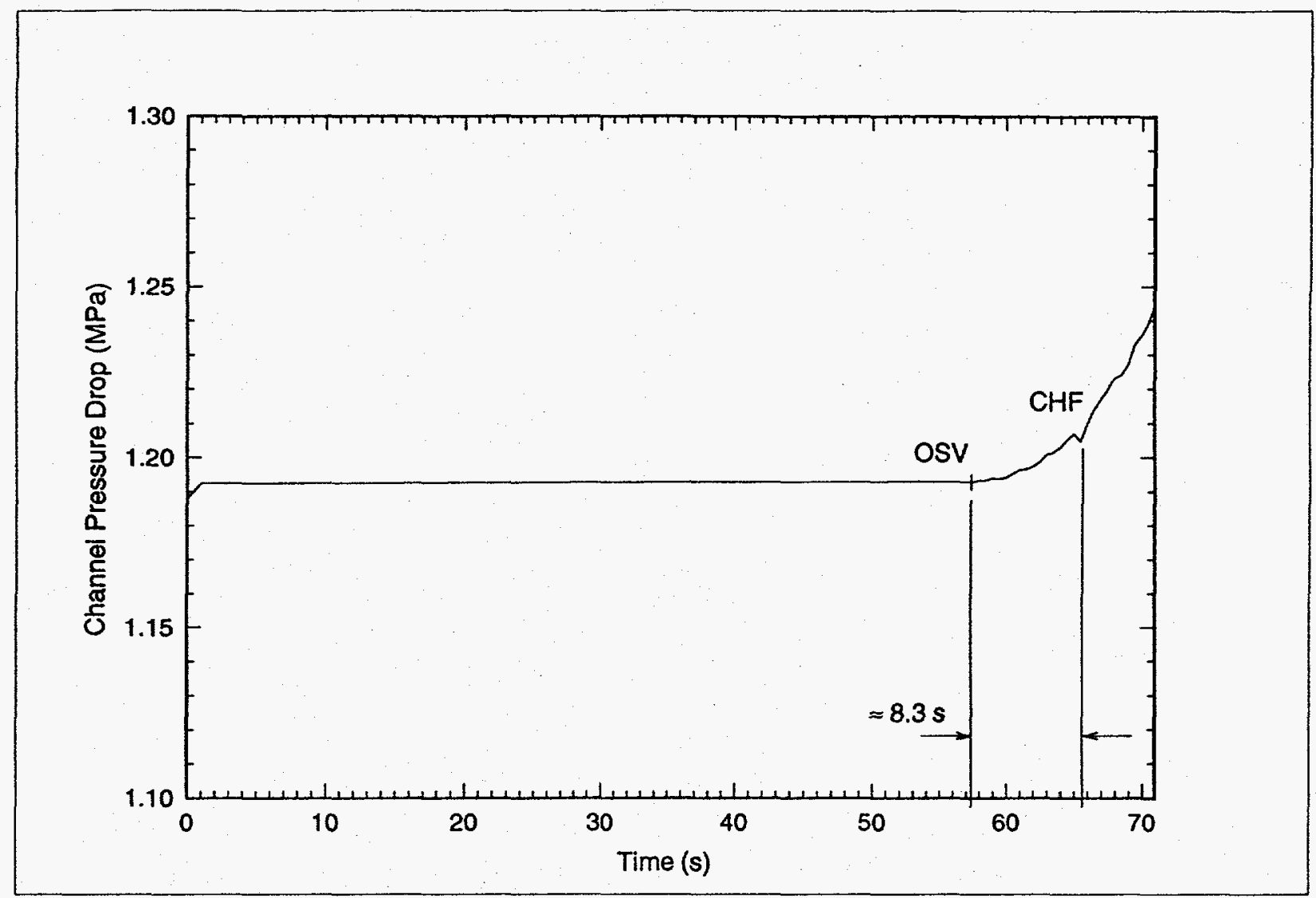

Fig. 9. Channel demand pressure drop for the exit depressurization transient case using 95 axial nodes in RELAP5. 